


About IJMA
International Journal of Medical Arts is the Official Scientific Journal
of the Damietta Faculty of Medicine, Al-Azhar University, Egypt
It is an International, Open Access, Double-blind, Peer-reviewed,
monthly-published (starting January 2022) Journal
The First Issue was published in July 2019
Published under the following license: Creative Commons
Attribution-ShareAlike 4.0 International Public License (CC BY-SA
4.0).
The Egyptian Knowledge Bank hosts the web site and supports
IJMA follows the regulations of the International Committee of
Medical Journal Editors
IJMA is a member of the International Society of Managing and
Technical Editors
IJMA is indexed in the "Directory of Open Access Journals"
[Indexed on 15 January 2021], Index Copernicus and J-Gate [29-6-
IJM21].
IJMA Listed in
"Publons", "Academic resource index [ResearchBib]", "Electronics journal
Jibrary", "Eurasian Scientific Journal Index", World Catalogue of Scientific
WorldCat and "Citefactor"




Available online at Journal Website
https://ijma.journals.ekb.eg/
Main Subject [Gynecology and Obstetrics]

Original Article

\title{
Anterior Colpourethroraphy [El Hemaly Operation] for Treatment of Female Stress Urinary Incontinence: A urodynamic Evaluation
}

\author{
Faisal Ali Mustafa ${ }^{*[1]}$, Zainab Shehata Sayed ${ }^{[1]}$; Maher Gawish ${ }^{[2]}$ \\ ${ }^{1}$ Department of Obstetrics and Gynecology, Faculty of Medicine, Al-Azhar University, Assiut, Egypt. \\ ${ }^{2}$ Department of Urology, Faculty of Medicine, Al-Azhar University, Assiut, Egypt.
}

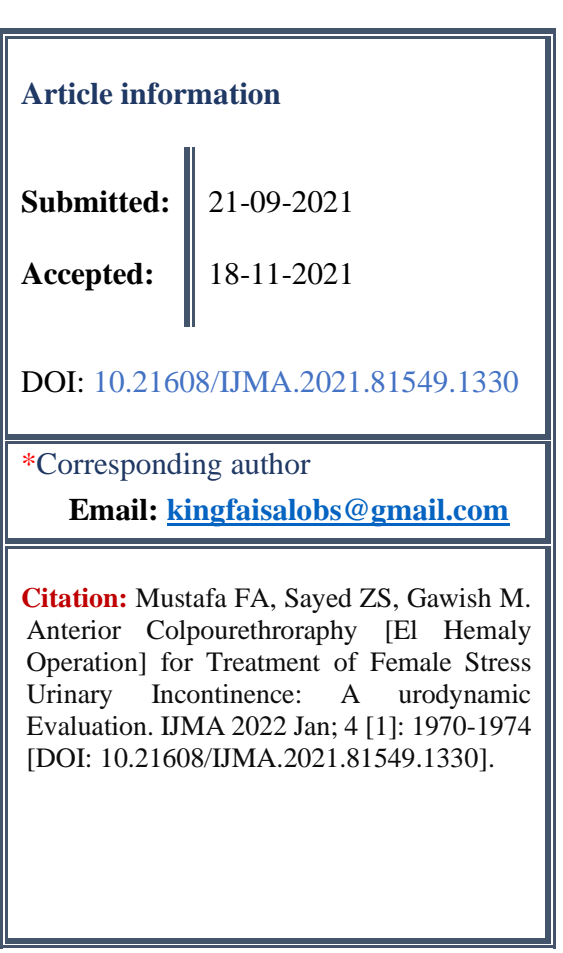

\begin{abstract}
Background: Urinary incontinence [UI] is any urinary leak. It is a common and stressful health condition, which have an impact on patient's quality of life. It is more prevalent among women than men [2:1]. Risk factors include pregnancy, parturition, and menopause.

The aim of the work: The work study aimed to assess the value of urodynamics prior to stress incontinence surgery [SUI] with regard to outcome, as well as the costs, in women complaining from SUI.

Patients and Methods: This study carried out at the department of Obstetrics and Gynecology, Al-Azhar University Hospital [Assiut Branch]. It included 20 females, 30-40 years old, who were suffering from SUI free from any medical diseases or previous surgeries of urinary tract. All were submitted to urodynamic study before surgical correction by anterior colpourethroraphy [El Hemaly operation] and outcome was documented.

Results: The results of filling phase revealed that, the infused and bladder filling were significantly increased, while volume lost through leakage was significantly reduced after intervention than corresponding values before surgery [514.3 \pm 155.29 , $473.2 \pm 174.89$ and $55.8 \pm 50.96$ vs $359.3 \pm 193,238.25 \pm 142.59$ and $120 \pm 68.17$, respectively]. Sensation results revealed that, there was statistically significant increase of volume at first sensations, first desire, normal desire, strong desire, urgency and maximum cystometric capacity, when compared to volumes before surgery.

Conclusion: Anterior colpourethroraphy [El-Hemaly operation] was an effective option, technically feasible with low complications and consistent patient satisfaction. Urodynamic study remains the most comprehensive method in the assessment of the bladder and urethral function.
\end{abstract}

Keywords: Stress Urinary Incontinence; Urodynamics; Urethroraphy, Colporrhaphy; El Hemaly Operation.

This is an open-access article registered under the Creative Commons, ShareAlike 4.0 International license [CC BY-SA 4.0] [https://creativecommons.org/licenses/by-sa/4.0/legalcode.

\section{INTRODUCTION}

Urinary incontinence, or involuntary passage of urine, is recognized as any urinary leak. It is a stressful condition, that affects the patient's quality of life. In addition, it is more common in females than males [2: 1 female to male ratio]. Female specific risk factors include pregnancy, parturition, and menopause. The condition represented a crucial issue in old women. Urinary leak is usually due to an underlying medical disease. However, it is under- reported. Enuresis is the term used to denote urinary incontinence chiefly in pediatrics, and more specifically nocturnal enuresis ${ }^{[1,2]}$.

Stress urinary incontinence [SUI] besides being a medical problem, it is also a social problem for many females. Great efforts had been done to elucidate the STI pathogenesis. However, the condition become more puzzling. Sir Eardely Holland, for the first time in 1992, assigned the specific name "Stress urinary incontinence" to the involuntary urine leak 
due to dramatic rising of pressure [either intrabdominal or intravesical] [e.g., with coughing or sneezing]. Subsequently, the disease was categorized into two medical conditions, the genuine SUI and instability of detrusor muscle. However, in females, a mixed types of SUI and urgency are the most common presented UI types ${ }^{[1,2]}$. In 1996, another trial was designed to elucidate the SUI pathogenesis was made. Accordingly, SUI was mainly due to an internal urethral sphincter wall defect. This defect was mainly due to rupture and/or splitting of the collagenous tissue layer. This rupture or splitting inevitably leads to weakness of the wall of the internal urethral sphincter. Gynecological and urological scientific committees' guidelines recommended urodynamic studies before invasive surgical interventions [uroflowmetry] for SUI. Postoperative urodynamic assessment [Cystometry] was also recommended ${ }^{[3,4]}$.

In uroflowmetry, patients were advised to drink two liters of water, one before arrival and the other on arrival to the urodynamic study unit. Then, patients were advised to hold urination until completely full, and then they were permitted to void into the uroflow-meter in privacy ${ }^{[5,6]}$. The uroflow curves were obtained in a graphic recording. The volume of post-void residual urine was habitually measured by transurethral catheter after voiding ${ }^{[7,8]}$.

For cystometry, patients were advised to achieve supine position on a couch to permit passage of catheters into the bladder and the rectum to estimate pressure inside the bladder and abdomen, respectively. In addition, bladder sensation, activity of detrusor muscle, compliance of the bladder, urethral function and the capacity of the bladder were measured during the bladder filling phase ${ }^{[9]}$.

During voiding, the intra-vesical pressure and flow rate were determined in a continuous pattern measured and graphically recorded. The results are crucial to the clinician ${ }^{[10]}$. Urethroraphy [Anterior colpourethroraphy] is a surgical intervention established to manage SUI, detrusor instability [DI], and mixed type UI. It is a simple operation, carried out through vaginal route, and aiming to restore normal anatomy to permit the internal urethral sphincter to preserve urinary continence and associated with repair of cystocele ${ }^{[11]}$.

\section{THE AIM OF THE WORK}

The current study aimed to assess the value of urodynamics prior to stress incontinence surgery [SUI] with regard to outcome, as well as the costs, in women with symptoms of SUI.
PATIENTS AND METHODS

This prospective study was completed at the Department of Obstetrics and Gynecology, AlAzhar university Hospital [Assiut Branch]. This study included 20 females, aged [30-40] years suffering from SUI and free from any other medical diseases or previous surgeries that affect urinary tract [UT].

An informed written consent was signed by each participant and her husband, for urodynamic study and surgical correction. All females were submitted to urodynamic study for preoperative confirmation and assessment. Urodynamics has been performed according to International Continence Society standards and consists of filling cytometry and uroflowmetry. El Hemaly operation was done to all patients then postoperative urodynamics was done for all patients.

All females were assessed clinically by history taking [personal, complaint, history of present illness, past history, family history, menstrual and obstetric history].

Inclusion criteria: Patients suffering from SUI, at their middle age [30-40 years], who signed an informed consent, with negative history for previous urogynecological surgery or chronic medical diseases, were included in the study. However, patients with history of medical diseases as diabetes and hypertension, who had previous urogynecological surgery, who had bladder mass or discovered at time of examination, with active urinary tract infection, were younger than 30 years or older than 40 years, patients in the postpartum period and/or refused to participate in the study were excluded.

\section{Pre-operative workup}

After consent to participate, each woman was advised to keep a voiding follow up sheet to estimate the disease severity and to specifically monitor the preoperative situation and easily follow up the health condition postoperatively. Woman then clinically assessed, the residual urine was measured, urine sample was analyzed followed by bacteriological culture and sensitivity was performed. Urodynamic evaluation was then performed and repeated postoperatively. The tests used were cystometry, estimation of urethral pressure, stress cystourethral pressure and leak-point pressure were performed. After that, the anterior urethroraphy through the vaginal route was performed for each female. All operations were performed under general or regional 
[spinal or epidural] anesthesia, while patient was in the lithotomy position. Patients were draped after cleaning up, catharized and urine samples were drawn and sent for analysis.

\section{Procedure}

A posterior vaginal wall speculum was introduced, with visualization of the uterine cervix. Two tenaculum were used to grasp the anterior lip of the cervix. An adrenaline solution [10-20 ml] [diluted 1/200,000, adrenaline: saline] was used in subvaginal infiltration, to help the separation of the anterior vaginal wall from the bladder and the urethra; besides its hemostatic effect. Usually, a surgical incision was required through the anterior vaginal wall to complete the procedure. The bladder was moved backwards to its normal position. The vaginal wall had been folded of its edges in a duplicated manure. Sutures were made in tissues between the bladder and the vagina from inner edge of a fold to outer edge of the other. Then suturing the outer edge of first fold to inner edge of second fold. These manures which hold the vaginal walls to a correct position which duplicated vaginal walls and strengthen vagina. so, filling and voiding had been better, and symptoms were disappeared gradually.

\section{Post operative assessment:}

On the second day after intervention, the catheters and the vaginal packs were removed. Free voiding was permitted for one day before discharge. The follow up visits were arranged after 1, 3, and 6 months postoperatively. During each of these visits, patient was clinically evaluated and urodynamic studies were performed to complete the assessment. Patients subjectively assess themselves by recording any symptoms, the condition of incontinence, SUI, DI, frequency and urgency of urination, nocturnal enuresis and any troubles related to the voiding process. Subjective cure was defined if there was no urinary leak on provocation and the patient had no problems related to voiding [e.g., retention, urgency or residual urine of more than $50 \mathrm{ml}]$. On the other side, the objective success [cure] was estimated on the clinical, urodynamic and ultrasonographic basis. The principal indicators of objective success were absences of any urine leak with increased intraabdominal pressure, significant increase of urethral closure, and capacity of the bladder, absent contractions of detrusor muscle during filling phase of the bladder, increased level of first void sensation, increased transmission ratio to above one, increased abdominal leak-point pressure and decreased postvoiding residual urine to $<50 \mathrm{ml}$. On 3Dultrasound, compact thick wall defects were disappeared, with urethro-vesical angles restoration and rectification of the apparent collapse of the urethra. Improvement was nominated as marked drop of the leakage incidents, to > $50 \%$ the preoperative episodes number. Also, no voiding problems were reported by the patient, and urodynamic and ultrasonographic variables were significantly improved than preoperative values.

\section{Statistical analysis:}

The arithmetic mean [a measure of central tendency] and standard deviations [a measure of dispersion] were calculated for normally distributed continuous variables. Paired samples, $[t]$-test was used to compare the same variable at two different points of time [e.g., before and after surgical intervention]. Wilcoxon signed-rank test was used instead of paired samples [t] test if data was abnormally distributed. Variables were examined for normal distribution by Kolmogorov Smirnov test. A two-tailed $\mathrm{p}<0.05$ was considered significant. All analyses were performed with the IBM SPSS 20.0 software.

\section{RESULTS}

In the current work, patient's age ranged between 31 to 40 years. The mean age was $37.15 \pm 2.85$ years. The results of filling phase revealed that, the infused and bladder filling were significantly increased, while volume lost through leakage was significantly reduced after colpourethroraphy when compared to corresponding values before surgery [Table 1]. Sensation results at bladder filling level after surgery revealed that, there was statistically significant increase of volume at first sensations, first desire, normal desire, strong desire, urgency and maximum cystometric capacity, when compared to volumes before surgery [Table 2].

Table [1]: Relation of filling phase results before and after colpourethroraphy [El Hemaly operation]

\begin{tabular}{|l|c|c|c|}
\hline Infused Volume [ml] & Before operation & After operation & \multicolumn{1}{|c|}{ P-value } \\
\hline Volume lost through leakage [ml] & $359.3 \pm 193$ & $514.3 \pm 155.29$ & $<0.001$ \\
\hline Bladder Filling [ml] & $120 \pm 68.17$ & $55.8 \pm 50.96$ & $<0.001$ \\
\hline
\end{tabular}


Table [2]: Relation of sensation results at bladder filling level before and after before colpourethroraphy [El Hemaly operation]

\begin{tabular}{|l|c|c|c|}
\hline & Before El Hemaly operation & After El Hemaly operation & P-value \\
\hline First sensation [ml] & $79.3 \pm 61$ & $267.8 \pm 114.5$ & $<0.001$ \\
\hline First desire [ml] & $164.35 \pm 136$ & $288 \pm 105$ & $<0.001$ \\
\hline Normal desire [ml] & $169.9 \pm 164$ & $365.3 \pm 91.7$ & $<0.001$ \\
\hline Strong desire [ml] & $133.25 \pm 139.9$ & $430.5 \pm 109.4$ & $<0.001$ \\
\hline Urgency [ml] & $437 \pm 111$ & $333 \pm 99.13$ & $<0.001$ \\
\hline $\begin{array}{l}\text { Maximum cystometric capacity } \\
\text { [ml] }\end{array}$ & $275.6 \pm 148.4$ & $537.94 \pm 148.6$ & $<0.001$ \\
\hline
\end{tabular}

Data are presented as mean \pm SD.

\section{DISCUSSION}

In this study pre- and post-operative urodynamic study for patients repaired with El Hemaly operation in 20 female patients with stress urinary incontinence are classified into pre- and postoperative study by urodynamic study. All were referred from Gynecological Department to Urology department at our university hospital for an assessment of their lower urinary tract function. Lower urinary tract symptoms, particularly the Incontinence-related symptoms, reported more frequently by women in the pre operatives than postoperative time in same patients, as reported previously ${ }^{[12]}$. Urodynamic results were in line with others where the existence of leak and residual urine was cornerstone for diagnosis of the condition ${ }^{[5,6]}$.

Petrou et al. ${ }^{[13]}$ investigated the role of urodynamic findings on the success following urethroraphy for stress urinary incontinence. They reported significant reduction of incontinence symptoms after surgery than preoperative symptoms. Other studies have confirmed that patients with severe pre-operative symptoms are surgically cured and urodynamic study was better for evaluation ${ }^{[14]}$.

Analysis urodynamic results revealed that all women with SUI had abnormal results of different types. This finding may indicate that the bladder hyper-compliance was one of frequently encountered abnormal urodynamic manifestations in female SUI. In addition, the voided volume was significantly increased in postoperative than preoperative time. During filling phase infused volume and bladder filling are more post-operative than pre-operative unlike volume leakage. The impaired bladder sensation, that allows accumulation of abnormally large volume of urine before the desire was felt, and may be the cause. The other urodynamic results include diminished sensation of the bladder, weak contractility of the detrusor muscle, DI, reduced bladder capacity, decreased amount at first desire and obstruction of the bladder outlet. There was significant difference in postoperative than preoperative urodynamic values. Bladder capacity and leakage are the most important cornerstone of urodynamic study, Bladder capacity is more post-operative repair, although leakage decreased. These findings are more preoperative due to change of intravesical pressure with anatomical disturbances that are repaired operatively. A similar finding was discovered ${ }^{[15]}$.

In cystometry, there was a high rate of bladder filling, which may result in an increase of intravesical pressure and threshold volume ${ }^{[3,4]}$. In addition, these rates of non-physiological filling may mechanically destruct the afferent limb of the micturition reflex, with subsequent generation of action potentials leading to an urge to void at volumes larger than normal. It was reported that a high filling rate was a principal factor in the induction of bladder smooth muscle hyperplasia, associated with urothelium and connective tissue hyperplasia ${ }^{[16]}$.

The main limitation of the study is the small sample size; in addition, this study relied mainly on the urodynamic study for as the main outcome for the evaluation of anterior colpourethroraphy [ElHemaly operation]. Other outcomes, especially patient satisfaction, are not significantly highlighted.

Finally, we could say that, urodynamic study was a good indicator of the improvement of stress urinary incontinence repaired by anterior colpourethroraphy [El-Hemaly operation]. Our patient's mean values were related to the presence of urodynamic abnormalities.

Conclusion: Anterior colpourethroraphy [E] Hemaly operation] for treatment of female stress urinary incontinence was an effective operation easily done with less complications and consistent patient satisfaction. Also, Urodynamic evaluation 
remains the comprehensive tool in the assessment of the bladder and urethral function.

\section{Financial and Non-financial Relationships and Activities of Interest}

None

\section{REFERENCES}

1. Lee EW, Kobashi KC. Mixed incontinence: what takes precedence in its management? Curr Urol Rep. 2014 Dec;15[12]:461. DOI: 10.1007/s11934-014-0461-y.

2. Welk B, Baverstock RJ. The management of mixed urinary incontinence in women. Can Urol Assoc J. 2017;11: S121-S124. DOI: 10.5489/cuaj.4584.

3. Kim HG, Park HK, Paick SH, Choi WS. Comparison of Effectiveness between Tension-Free Vaginal Tape [TVT] and Trans-Obturator Tape [TOT] in Patients with Stress Urinary Incontinence and Intrinsic Sphincter Deficiency. PLoS One. 2016; 11 [5]: e0156306. DOI: 10.1371/journal.pone.0156306.

4. Witkoś J, Hartman-Petrycka M. Will future doctors know enough about stress urinary incontinence to provide proper preventive measures and treatment? Med Educ Online. 2019 Dec; 24[1]:1685635. DOI: 10.1080/10872981.2019.1685635.

5. Serati M, Braga A, Torella M, Soligo M, Finazzi-Agro E. The role of urodynamics in the management of female stress urinary incontinence. Neurourol Urodyn. 2019 Aug;38 Suppl 4: S42-S50. DOI: 10.1002/nau.23865.

6. Brazzelli M, Javanbakht M, Imamura M, Hudson J, Moloney E, Becker F, et al. Surgical treatments for women with stress urinary incontinence: the ESTER systematic review and economic evaluation. Health Technol Assess. 2019 Mar; 23 [14]: 1-306. DOI: 10.3310/hta23140.

7. Cantu H, Sharaf A, Bevan W, Hassine A, Hashim H. Ambulatory urodynamics in clinical practice: A single centre experience. Neurourol Urodyn. 2019 Nov;38[8]:2077-2082. DOI: 10.1002/ nau.24153.
8. Al Mousa RT, Al Dossary N, Hashim H. The role of urodynamics in females with lower urinary tract symptoms. Arab J Urol. 2019 Apr 4;17[1]:2-9. DOI: 10.1080/2090598X.2019.1589931.

9. Kocher NJ, Damaser MS, Gill BC. Advances in Ambulatory Urodynamics. Curr Urol Rep. 2020; 21[10]:41. DOI: 10.1007/s11934-020-00989-w.

10. Sharma N, Chakrabarti S. Clinical Evaluation of Urinary Incontinence. J Midlife Health. 2018 AprJun; 9[2]:55-64. DOI: 10.4103/jmh.JMH_122_17.

11. Bianchi F, Squintani GM, Osio M, Morini A, Bana C, Ardolino G, et al. Neurophysiology of the pelvic floor in clinical practice: a systematic literature review. Funct Neurol. 2017 Oct/Dec;22[4]:173-193. DOI: 10.11138/fneur/2017.32.4.173.

12. van Leijsen SA, Kluivers KB, Mol BW, Vierhout ME, Heesakkers JP. The value of preoperative urodynamics according to gynecologists and urologists with special interest in stress urinary incontinence. Int Urogynecol J. 2012 Apr;23[4]:423-8. DOI: 10.1007/s00192-011-1565-2.

13. Petrou SP. Does Valsalva leak point pressure predict outcome after the distal urethral polypropylene sling? Role of urodynamics in the sling era. Int Braz J Urol. 2004;30[4]:355-6. PMID: 15679989.

14. Weber AM. Leak point pressure measurement and stress urinary incontinence. Curr Womens Health Rep. 2001 Aug;1[1]:45-52. PMID: 12112951.

15. Kaplan SA, Te AE, Young GP, Andrade A, Cabelin MA, Ikeguchi EF. Prospective analysis of 373 consecutive women with stress urinary incontinence treated with a vaginal wall sling: the ColumbiaCornell University experience. J Urol. 2000 Nov; 164 [5]:1623-7. PMID: 11025719.

16. Jung HJ, Yim GW, Jeon MJ, Kim SK, Bai SW. Preoperative maximum urethral closure pressure and Valsalva leak point pressure as predictive parameters for midurethral sling. J Reprod Med. 2009 Jul; 54[7]:436-40. PMID: 19691260. 


\section{$1=\sqrt{202(2)}$}

international Journal https://ijma.journals.ekb.eg/ Print ISSN: 2636-4174 Online ISSN: 2682-3780

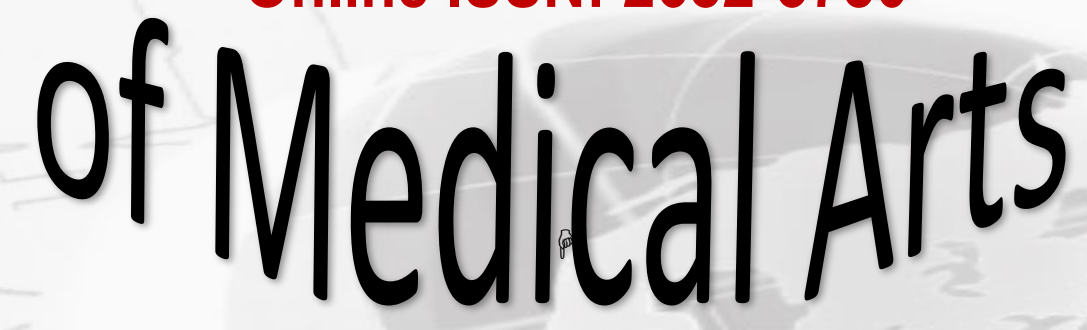

